\title{
What is the predictive value of MRI for the occurrence of knee replacement surgery in knee osteoarthritis?
}

\author{
J-P Pelletier, ${ }^{1}$ C Cooper, ${ }^{2,3}$ C Peterfy, ${ }^{4}$ J-Y Reginster, ${ }^{5} \mathrm{M}-\mathrm{L} \mathrm{Brandi}^{6}{ }^{6}$ O Bruyère, ${ }^{5}$

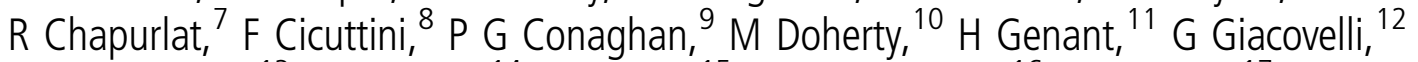 \\ M C Hochberg, ${ }^{13}$ D J Hunter, ${ }^{14}$ J A Kanis, ${ }^{15}$ M Kloppenburg, ${ }^{16}$ J-D Laredo, ${ }^{17}$ \\ T McAlindon, ${ }^{18} \mathrm{M}$ Nevitt, ${ }^{19} \mathrm{~J}-\mathrm{P}$ Raynauld, ${ }^{1} \mathrm{R}$ Rizzoli, ${ }^{20} \mathrm{C}$ Zilkens, $^{21} \mathrm{~F}$ W Roemer, ${ }^{22,23}$ \\ J Martel-Pelletier, ${ }^{1}$ A Guermazi ${ }^{23}$
}

\begin{abstract}
Handling editor Tore K Kvien
- Additional material is published online only. To view please visit the journal online (http://dx.doi.org/10.1136/ annrheumdis-2013-203631).

For numbered affiliations see end of article.

Correspondence to Professor J-P Pelletier, Osteoarthritis Research Unit, University of Montreal Hospital Research Centre (CRCHUM), Notre-Dame Hospital, 1560 Sherbrooke Street East,

Montreal, Quebec,

Canada H2L 4M1;

dr@jppelletier.ca
\end{abstract}

Received 15 March 2013 Revised 14 June 2013 Accepted 28 June 2013 Published Online First 25 July 2013
To cite: Pelletier J-P Cooper C, Peterfy C, et al. Ann Rheum Dis 2013;72:1594-1604.

\section{ABSTRACT}

Knee osteoarthritis is associated with structural changes in the joint. Despite its many drawbacks, radiography is the current standard for evaluating joint structure in trials of potential disease-modifying osteoarthritis drugs. MRI is a non-invasive alternative that provides comprehensive imaging of the whole joint. Frequently used MRI measurements in knee osteoarthritis are cartilage volume and thickness; others include synovitis, synovial fluid effusions, bone marrow lesions (BML) and meniscal damage. Joint replacement is considered a clinically relevant outcome in knee osteoarthritis; however, its utility in clinical trials is limited. An alternative is virtual knee replacement on the basis of symptoms and structural damage. MRI may prove to be a good alternative to radiography in definitions of knee replacement. One of the MRI parameters that predicts knee replacement is medial compartment cartilage volume/thickness, which correlates with radiographic joint space width, is sensitive to change, and predicts outcomes in a continuous manner. Other MRI parameters include BML and meniscal lesions. MRI appears to be a viable alternative to radiography for the evaluation of structural changes in knee osteoarthritis and prediction of joint replacement.

\section{INTRODUCTION}

Knee osteoarthritis involves structural changes in the whole joint, including cartilage, subchondral bone, the menisci, synovial tissue, muscles and ligaments, with associated clinical manifestations of pain and loss of function. ${ }^{1}$ The ultimate clinical outcome of osteoarthritis is often total joint replacement in the hip or knee, which is effective in managing symptoms and reversing loss of function in most patients, but is costly, not without risk of complications, and only effective for a limited length of time.

The current imaging standard for evaluating structural changes associated with osteoarthritis is radiographically measured joint space width or narrowing (JSW or JSN) (or interbone distance), which is considered a surrogate for tibiofemoral cartilage loss. ${ }^{2}$ Radiographic evaluation, however, has a number of drawbacks. ${ }^{3-5}$ Among other things, JSW depends on structures other than articular cartilage, including meniscal damage and extrusion, making it relatively inaccurate as a measure of cartilage loss. Also, radiography fails to detect many important osteoarthritis-associated pathological features that can be seen and assessed with MRI (figure 1). A recent population-based observational study demonstrated that approximately $90 \%$ of radiographically normal knees had one or more osteoarthritis-related feature on MRI. ${ }^{6}$ There are also technical challenges associated with radiographic assessment, such as positioning and alignment (figure 1). ${ }^{7}$ Despite these limitations, radiographic criteria are currently recommended for the evaluation of structural modification (JSN or JSW) in randomised controlled trials (RCT) of potential disease-modifying osteoarthritis drugs (DMOAD) by the regulatory agencies. ${ }^{8} 9$

MRI is a non-invasive technique used for assessing joint morphology in multiple tomographic planes, with direct visualisation of cartilage, subchondral bone, menisci and other joint tissues. MRI is an objective and reproducible technique that has been shown to be sensitive to change, although its value in RCT is not yet fully established. It may be useful at all phases of drug development to assess structural changes and their progression or improvement over time in response to DMOAD. MRI has been estimated to detect the presence of osteoarthritis with high specificity and moderate sensitivity compared with various reference standards, including radiography and arthroscopy. ${ }^{10}$ One disadvantage of MRI is that to date there has been no consensus on a standardised scale or scoring system. However, there have been a number of major advances in the past decade, in terms of the move from simple qualitative observation of structures to semiquantitative and quantitative analyses of structural changes. ${ }^{11}$ MRI holds much promise as an alternative to radiography in the evaluation of joint structure.

It was in this context that the European Society for Clinical and Economic Aspects of Osteoporosis and Osteoarthritis (ESCEO) organised a working meeting in October 2012 to discuss the role of MRI in the evaluation of osteoarthritis and the development of DMOAD, with a focus on the predictive value of MRI parameters for knee replacement surgery in osteoarthritis. This article summarises these discussions and presents a series of position statements. 
Figure 1 A 59-year-old woman with left knee pain for 3 months, with 1 week exacerbation. (A) Posteroanterior view of the left knee does not well delineate the tibiofemoral joint with tibial inter-rim margin exceeding $10 \mathrm{~mm}$. (B) Repeat radiograph on the same day shows better delineation of the tibiofemoral joint and small lipping at the medial tibial plateau (arrow) and equivocal medial tibiofemoral joint space narrowing. Radiographic positioning is problematical in clinical trials and usually comparison between visits is made difficult secondary to change in appearance in tibiofemoral joint between visits. (C) Coronal intermediate-weighted MRI shows a medial meniscal root tear (white arrow) with associated meniscal subluxation (black arrowhead). (D) Sagittal intermediate-weighted MRI shows diffuse cartilage loss at the posterior medial femoral condyle (arrows) with subchondral cystic changes. There is also a small joint effusion (star). The radiograph will not show this notable cartilage change because it is posterior and not part of the weight-bearing tibiofemoral joint. (E) Coronal T2-weighted fat-suppressed MRI shows a large medial tibial bone marrow hyperintensity (arrows), which is not immediately subchondral (note the presence of normal bone marrow, shown as hypointensity, between the tibial surface and the upper border of the hyperintensity (star), suggesting that this is non-degenerative in nature. Also, degenerative bone marrow lesions should be accompanied by degenerative tibial cartilage loss, but that is not present in this case. The only visible cartilage abnormality is a small fissure at the medial weight-bearing femur (arrowhead). (F) Sagittal T2-weighted fat-suppressed MRI shows a faint hypointense line (arrow) within the large bone marrow hyperintensity representing a subchondral fracture. The large bone marrow hyperintensity is indeed a bone reaction to the subchondral fracture and not degenerative bone marrow lesion seen in osteoarthritis.
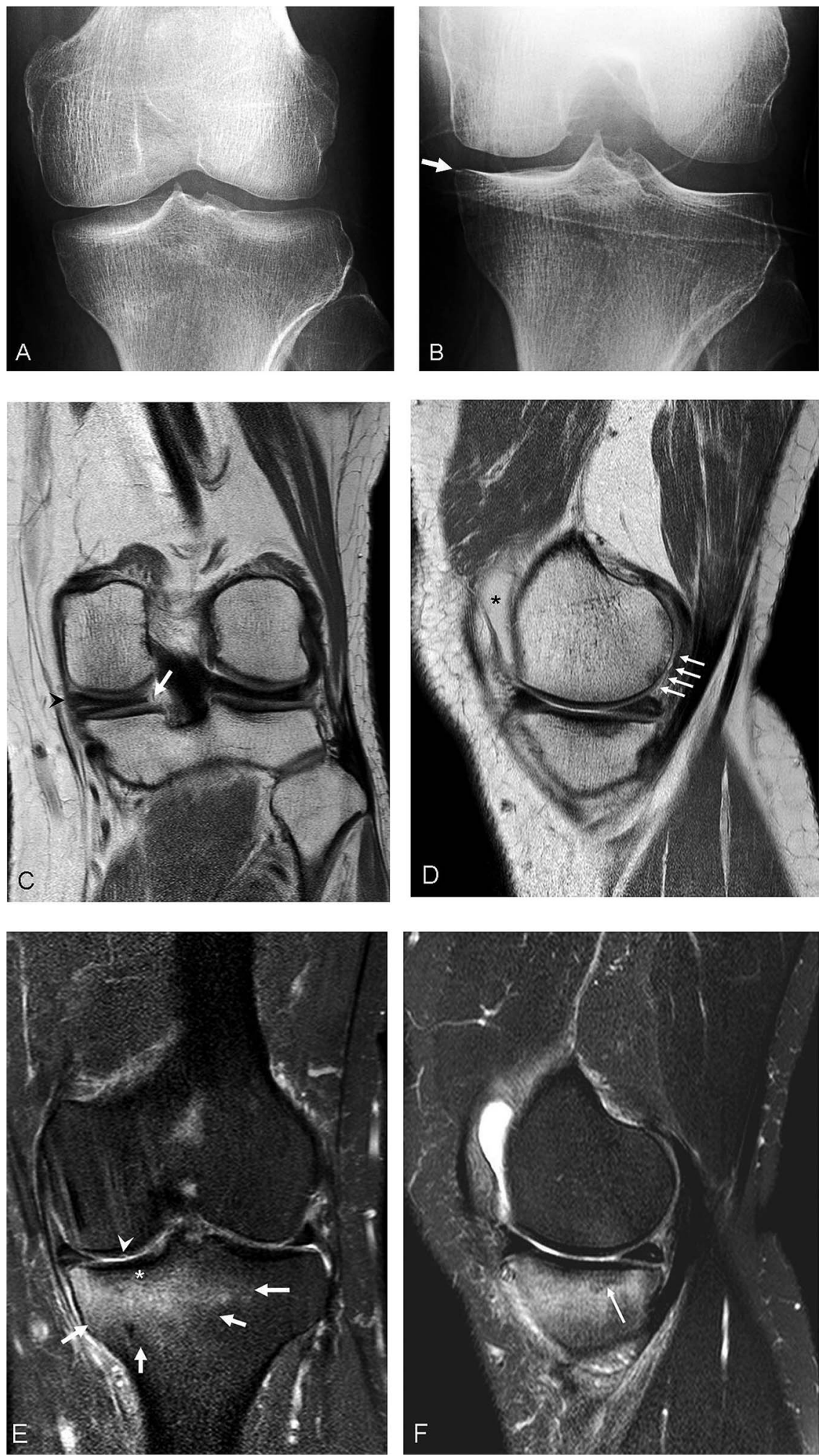

\section{METHODS}

Relevant articles, reviews and abstracts were identified through an initial search of PubMed/MEDLINE and EMBASE for English language articles published between 1994 and September 2012 using the terms: osteoarthritis, MRI (in title or as a major keyword), disease progression, treatment outcome, severity of illness, joint structure, bone marrow lesion (BML), cartilage volume, cartilage thickness, JSW, JSN, natural history, DMOAD, osteoarthritis agent/drug, arthroplasty, joint replacement, and surgery. Separate sub-searches were also performed using a cross-search of the above terms combined. The initial search yielded 91 items. Other items were identified from the reference lists of selected articles and the presentations made during the ESCEO meeting. The members of the working group assessed the relevance of these articles for the task at hand: discussion of the specific role of MRI in the evaluation of osteoarthritis; development of DMOAD; and prediction of knee replacement. 


\section{RESULTS}

\section{MRI of joint structures in knee osteoarthritis}

One major advantage of MRI is that it provides a comprehensive view of many of the joint structures. ${ }^{12}$ The joint structure most commonly measured by MRI in osteoarthritis of the knee is cartilage, specifically its changes in volume and thickness over time. Other information provided includes the presence of synovitis and synovial fluid effusions, BML, meniscal damage, osteophytes, muscle, bursae, ligaments, fat pad and defects in bone. To ensure accurate evaluation of osteoarthritis, investigators need to select appropriate pulse sequences suited for the purpose of each study. ${ }^{13}$ Moreover, readers of MRI need to be aware of differential diagnoses for images, which may mimic osteoarthritis, such as BML, which can be observed in traumatic and non-traumatic pathologies (figure 1). ${ }^{14}$ For these reasons, MRI should be interpreted by trained individuals, ideally with experience in clinical MRI of the knee, particularly in the context of clinical trials in which protocols are too elaborate for use in routine clinical practice.

In recent years, there has been a series of advances in the solutions for MRI reading. These include semiquantitative methods and quantitative technologies involving semiautomated and, more recently, fully automated systems. The development of new technological segmentation took into account some of the problems that were encountered with the previous methods.

\section{Semiquantitative methods}

Semiquantitative techniques are available for most of the joint structures relevant to osteoarthritis, including cartilage, synovium, menisci and subchondral bone. ${ }^{15}$ They are applicable in large-scale RCT. The most commonly used semiquantitative methods for evaluating cartilage are whole organ MRI score (WORMS), Boston Leeds osteoarthritis knee score (BLOKS) and MRI osteoarthritis knee score (MOAKS). ${ }^{16-18}$ These methods can assess lesions in the whole knee and in defined anatomical sub-regions.

WORMS considers 14 articular features covering cartilage damage, BML, osteophytes, meniscal damage, cruciate and collateral ligament damage, synovitis/effusion, intra-articular loose bodies, and peri-articular cysts/bursitis in up to 16 regions providing whole-organ multi-feature assessment. ${ }^{17}$ The BLOKS method covers the evaluation of BML, cartilage, osteophytes, synovitis and effusions in nine regions. ${ }^{16}$ WORMS and BLOKS have good to excellent reliability, ${ }^{19} 20$ inter-reader agreement ( $\kappa$ 0.69-1.0 and 0.65-1.0, respectively), ${ }^{21}$ similar results for the prevalence and severity of cartilage loss (inter-method $\kappa$ for cartilage lesions, 0.66-0.95), and similar sensitivity and specificity to radiographic joint space loss (specificity $88 \%$ vs $86 \%$ ). ${ }^{19} 20$ The MOAKS system further refines the scoring of BML, cartilage and meniscal morphology. ${ }^{18}$ MOAKS has also been shown to have very good to excellent reliability $(\kappa 0.61-1.0$, for most measures of inter-observer and intra-observer). ${ }^{18}$

Semiquantitative methods can therefore evaluate the progression of lesions in the different sub-regions of the knee and provide a comprehensive assessment of the knee lesions crosssectionally and longitudinally. ${ }^{15}$

In order to detect longitudinal structural changes with higher sensitivity, 'within-grade' scores have been introduced and used to record changes observed between time points that do not fulfil the criteria in the original integer grading scale. ${ }^{21}$ Despite not being part of the published grading systems, incorporating recording of within-grade changes increases the sensitivity to change of semiquantitative assessments. ${ }^{22}$ The association of within-grade changes with risk factors and outcomes suggests that they are clinically relevant. ${ }^{22}$

\section{Quantitative methods}

The developed semi-automated and fully automated quantitative MRI technologies can assess joint tissues, including cartilage volume and thickness, ${ }^{3}$ 23-26 both globally and regionally. Quantitative MRI was also developed to assess the volume of synovial fluid, ${ }^{27}$ synovial thickness, ${ }^{28}$ subchondral $\mathrm{BML}^{29}$ and osteophytes. $^{29}$ These quantitative joint tissue assessment technologies were shown to have very good to excellent reliability.

Parametric mapping techniques, such as delayed gadolinium-enhanced MRI of cartilage (dGEMRIC), chemical exchange saturation transfer (GAG-CEST) T1 $\rho$ and sodium MRI provide direct or indirect measures of cartilage glycosaminoglycan content, whereas T2 mapping, diffusion-weighted imaging and diffusion tensor imaging probe cartilage water content and the integrity of the collagen matrix. These techniques can be useful for quantifying early disease, ${ }^{3}{ }^{30}$ but experience in their performance in multicentre clinical trials is still limited. Gadolinium enhancement may lead to rare but potentially serious side effects, which has led to a warning from the US Food and Drug Administration, ${ }^{31}$ limiting its use.

\section{Cartilage}

Characterisation of cartilage damage is central to the assessment of osteoarthritis. Quantitative methods involve threedimensional reconstruction to measure cartilage volume and thickness, and their change over time, and can be semiautomated or fully automated. ${ }^{32-26}$ These methods also effectively evaluate the morphological characteristics of articular cartilage, or quantify regional cartilage loss. Progression of the WORMS cartilage score, ie, cartilage loss, is known to correlate with JSN in patients with knee osteoarthritis. ${ }^{32}$ Semiquantitative as well as quantitative scoring methods have been demonstrated to have adequate validity, accuracy, reliability and sensitivity to detect change in cartilage damage. ${ }^{11} 33{ }^{34}$ As an example, in one study, the intra-reader coefficient of variation (RMS CV\%) for repeated measures was $2.2 \%$ for the quantitative global cartilage volume and $1.2 \%$ and $2.6 \%$ for the medial and lateral compartments, respectively. ${ }^{35}$ These values were very similar in another study. ${ }^{36}$ For evaluating focal cartilage defects, multiple pulse sequences are recommended. ${ }^{34} 3738$

Fully automated technology can provide accurate and precise quantitative assessment, with reduced inter-observer variability for reliable analysis of large patient cohorts (eg, the Osteoarthritis Initiative cohort (OAI)) and RCT. With regard to the choice of parameters between cartilage volume or thickness, a similar level of sensitivity to change was reported in patients with knee osteoarthritis. ${ }^{39}$ Moreover, the potential for gaining statistical power by measuring change in these parameters in central weight-bearing knee sub-regions-where cartilage loss is usually the greatest-is limited by the fact that from one patient to another the site of the focal cartilage loss is highly variable. ${ }^{39}$ A comparative RCT study in patients with knee osteoarthritis followed over 2 years showed that quantitative measurement of changes in cartilage volume loss was more sensitive than semiquantitative methods, suggesting that quantitative methods may be more useful for determining treatment effects. ${ }^{34}$

\section{Synovitis and synovial fluid effusion}

Synovitis is a common feature of knee osteoarthritis and occurs in nearly $90 \%$ of referred patients. ${ }^{40}$ Synovitis and synovial 
fluid effusion can be measured by MRI using quantitative or semiquantitative methods. ${ }^{16-18}$ 41-43 The MOAKS study uses two new terminologies 'Hoffa-synovitis' and 'effusionsynovitis. ${ }^{18}$ Hoffa-synovitis is the presence of hyperintensity within Hoffa's fat pad, and acts as a surrogate marker for synovitis on non-contrast-enhanced MRI. Effusion-synovitis is synonymous with 'joint effusion', although the term can indicate that MRI-detected joint effusion equals both inflamed synovium and synovial fluid. Quantitative MRI evaluation of synovial membrane volume has been shown to be strongly associated with the severity of knee osteoarthritis, in terms of radiographic Kellgren-Lawrence (KL) grade, JSN, JSW and BML. ${ }^{28}$ The literature suggests that contrast-enhanced MRI can accurately assess the extent of synovitis. ${ }^{42} 44 \quad 45$ Although synovitis and effusion can be evaluated by both non-enhanced and gadolinium-enhanced MRI, and contrast enhancement helps to differentiate the thickened and inflamed synovium from synovial fluid, ${ }^{28} 444647$ thus far, no clinical trials for DMOAD have utilised contrast-enhanced MRI, mainly due to the additional cost and potential rare side effects of gadolinium. ${ }^{31}$

A fully automated technology to quantify synovial fluid using non-contrast-enhanced MRI sequences showed that fluid volume correlated with data from phantoms and joint aspiration, with magnification by a factor of 3.4 for MRI. ${ }^{27}$ In another study, the effusion volume measurement using semiquantitative methods based on non-enhanced compared to contrast-enhanced sequences resulted in a magnification of the effusion volume by a factor of 1.9. ${ }^{45} 47$ The difference in the amount of synovial fluid as measured by aspiration and MRI is likely to be related to the incomplete drainage of the joint with the former method, which can be considerably difficult in many patients.

\section{Bone marrow lesions}

The presence of BML in knee osteoarthritis has been associated with symptoms and cartilage loss. ${ }^{48-58}$ Although it is recommended that BML be evaluated using fluid-sensitive fast spin echo sequences (eg, T2 weighted, proton density weighted or intermediate weighted) with fat suppression, ${ }^{59}$ in a recent study, the sensitivity to change of gradient echo and water-sensitive intermediate-weighted sequences in the assessment of BML prevalence and size change over time were similar. ${ }^{60}$ In knee osteoarthritis patients, the BML size and score have been shown in many studies to fluctuate over time, ${ }^{54565960}$ and the results have been found to be variable from one study to another. BML may decrease or increase in size, or resolve completely. The development of new BML is also common.

BML can be assessed using semiquantitative techniques such as WORMS. ${ }^{17}$ However, a fully automated method to quantify BML in knee osteoarthritis has recently been published. ${ }^{29}$ Most BML changes appear to occur in the medial compartment, with similar prevalence in the femur and tibia, followed by the patellofemoral compartment, with relatively few changes in the lateral compartment. ${ }^{55}$

\section{Meniscal lesions}

Damage to the menisci due to degeneration or injury increases the risk of developing knee osteoarthritis. ${ }^{61}$ Meniscal lesions can be assessed by MRI via either quantitative or semiquantitative approaches. ${ }^{62}$ In the semiquantitative approach, meniscal tears and meniscal extrusion are the two main types of lesions that are scored in knee osteoarthritis, and both are believed to be important markers of disease. ${ }^{63}$ Meniscal tears have been associated with cartilage loss 57586264 and knee pain, ${ }^{65}$ and meniscal extrusion with knee malalignment and cartilage damage. ${ }^{57586266}$

\section{Predicting clinical endpoints with MRI-based structural endpoints \\ Clinical endpoints in knee osteoarthritis}

One of the major challenges in current research on osteoarthritis is the absence of precisely defined clinical endpoints, which complicates the assessment of the disease, particularly in the early stages, and the development of DMOAD. Patient-centred outcomes, evaluating pain or symptoms, are often too indirect or non-specific. Although of key clinical importance, they often show poor correlation with structural change, which challenges studies evaluating DMOAD activity. Osteoarthritis structural outcomes are a better option, but the question of how well certain biomarkers, including MRI measurements, relate to clinical outcomes remains uncertain.

Joint replacement is one of the ultimate outcomes of clinical relevance in knee osteoarthritis. Indications for joint replacement include pain, functional impairment and structural changes on radiography. The severity of structural change is not an indication in most clinical guidelines; disability and participation restriction are the main features to consider. The advantages of joint replacement as a primary outcome in clinical trials are that it is a good marker of end-stage knee osteoarthritis, it is dichotomous and easy to document, and it improves pain and function in the majority of patients. It is an expensive procedure (approximately $€ 6800$ (US\$8900) per knee replacement in 2009), ${ }^{67}$ although it is cost-effective in cases with severe symptoms or substantial functional limitations. ${ }^{68}$ Germany and the USA lead the world in the rate of knee replacement surgery (213 procedures per 100000 population) (figure 2). ${ }^{69}$ With more than 600000 procedures per year in the USA, the aggregate cost to the USA is US $\$ 9$ billion. ${ }^{70}$ Switzerland's population is one tenth that of Germany's, but it has a knee replacement rate (200 per 100000 population) that is comparable to that of Germany and the USA. The rate of knee replacement in the USA nearly doubled in the past decade. In Denmark it almost tripled (figure 3). ${ }^{69}$ In the USA, the number of knee replacements is projected to increase to 3000000 per year by 2030 , amounting to an estimated cost of US\$45 billion. Therefore, reducing the number of knee replacements would represent a major socioeconomic benefit. Even delaying surgery by a few years will ultimately decrease the total number of knee replacements.

There are a number of limitations to using knee replacement as a primary endpoint in large-scale RCT. First, knee replacement is less relevant in patients with mild structural changes, at which stage the use of DMOAD may be more effective. Moreover, rates of knee replacement may be affected by economic and cultural influences. For example, country-to-country variations may occur due to the differing prevalence of osteoarthritis, differing capacities to deliver and cover the cost of the procedure, and differing national guidelines and practices. ${ }^{67}$ Other confounding factors are comorbidities and patient/provider preferences, which include the effects of availability based on socioeconomic status in some countries. Time to surgery may therefore vary among patients, physicians and geographical locations. Second, the proportion of patients receiving knee replacement is relatively small, with only approximately $0.1 \%$ of the European population over the age of 50 years receiving the procedure annually. To achieve adequate statistical power, DMOAD trials based on this endpoint would have to include large populations followed over a long duration. Finally, and 
Figure 2 Knee replacement surgery per 100000 population in 2009 (or nearest year). Source: Health at a Glance. OECD 2011 (available at http:// dx.doi.org/10.1787/888932524773). ${ }^{69}$ OECD, Organisation for Economic Cooperation and Development includes 34 member countries (Australia, Austria, Belgium, Canada, Chile, Czech Republic, Denmark, Estonia, Finland, France, Germany, Greece, Hungary, Iceland, Ireland, Israel, Italy, Japan, Korea, Luxembourg, Mexico, The Netherlands, New Zealand, Norway, Poland, Portugal, Slovak Republic, Slovenia, Spain, Sweden, Switzerland, Turkey, UK, USA).

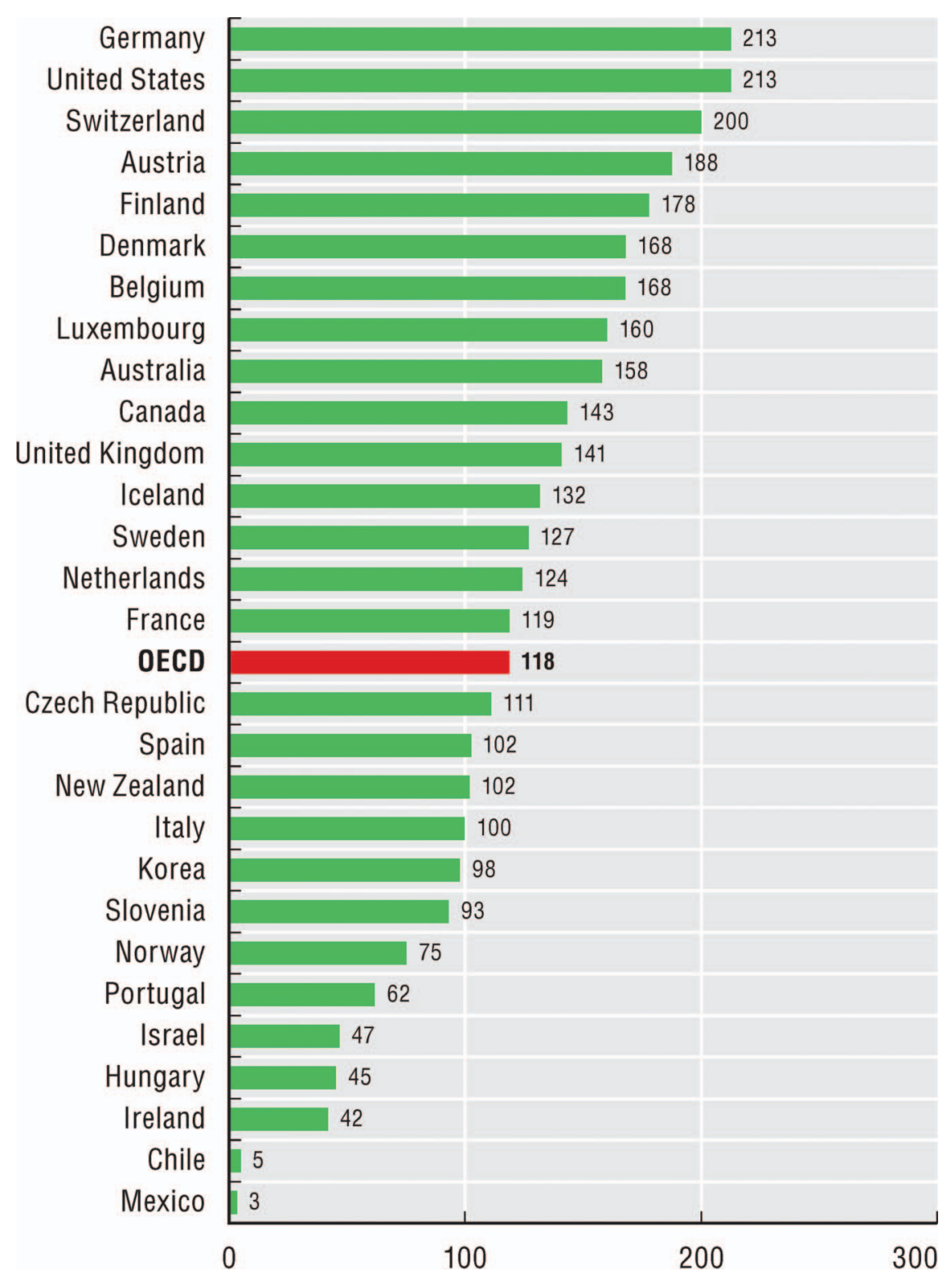

perhaps most importantly, there is no consensus on the precise definition of joint failure, which refers to the loss of joint function (as assessed by various functional measurement tools), which is consequent on the multiple tissue pathologies that comprise the osteoarthritis process: cartilage loss, subchondral bone reaction, synovial inflammation, meniscal and ligamentous damage.

With these issues in mind, the Osteoarthritis Research Society International/Outcome Measures in Rheumatoid Arthritis Clinical Trials initiative proposed an alternative primary outcome of virtual knee replacement. ${ }^{71}$ This composite index comprises domains on pain, functional disability and radiographic structural damage, and was proposed as a surrogate outcome for the evaluation of DMOAD in RCT. It was tested in a sample of 1379 patients from eight RCT in knee osteoarthritis. Even for virtual knee replacement, the authors concluded that very large sample sizes and long follow-up times would be necessary to attain the power required to detect between-group differences in DMOAD trials. ${ }^{71}$ Similar hurdles were encountered in the field of osteoporosis when definitions based on bone mineral density were devised. One solution to this may be to use a more sensitive measure of structural disease progression, assuming good predictive validity, such as MRI.

Evidence for MRI parameters as a predictor of knee replacement The relationship between MRI measurements and clinical symptoms of osteoarthritis has been studied in depth. There appears to be a moderate to strong association between MRI-measured BML and synovitis or synovial effusions and increasing symptoms, but a weak association between MRI cartilage loss or meniscal tears and symptoms. ${ }^{33} 72$ The correlates between measurements from MRI and those from radiography and other techniques for evaluating osteoarthritis are well established, but there have been few studies on the predictive power of MRI measurements for the clinical outcome of knee replacement. A systematic review performed in 2009 identified 243 papers on the concurrent and predictive validity of MRI-based measurements of structural change in osteoarthritis, but only three papers on the predictive value with regard to joint replacement. ${ }^{33}$ Interestingly, all three of those studies reported a statistically significant association between changes in MRI-based parameters and joint replacement $(\mathrm{p}<0.05) .^{73-75}$ Since then, there have been further 


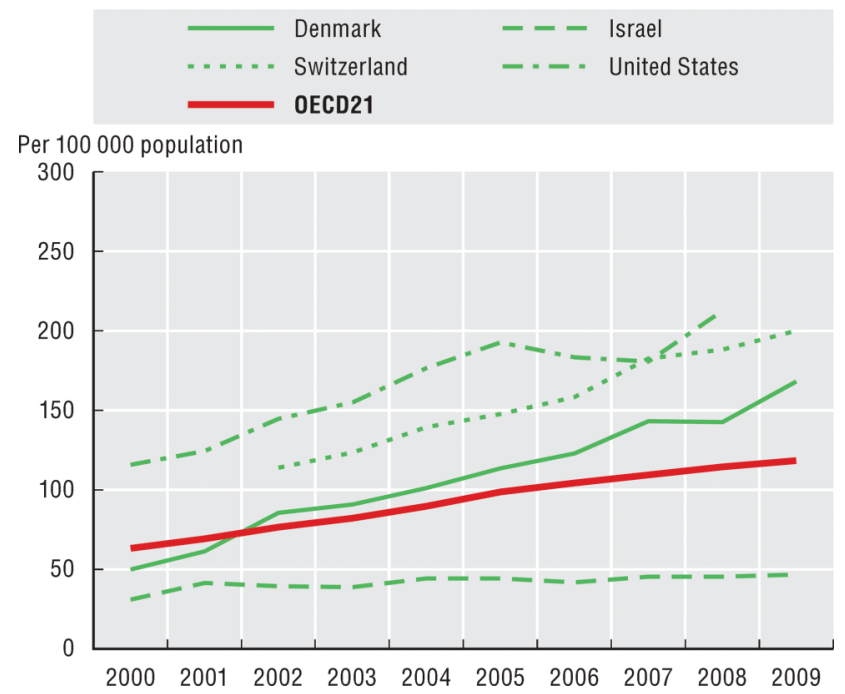

Figure 3 Trend in knee replacement surgery, 2000-9, selected countries. Source: Health at a Glance. OECD 2011 (available at http:// dx.doi.org/10.1787/888932524811). ${ }^{69}$ OECD, Organisation for Economic Cooperation and Development includes 34 member countries (Australia, Austria, Belgium, Canada, Chile, Czech Republic, Denmark, Estonia, Finland, France, Germany, Greece, Hungary, Iceland, Ireland, Israel, Italy, Japan, Korea, Luxembourg, Mexico, The Netherlands, New Zealand, Norway, Poland, Portugal, Slovak Republic, Slovenia, Spain, Sweden, Switzerland, Turkey, UK, USA).

publications, ${ }^{76-83}$ all with significant results. The results of the studies are summarised in table $1 .^{73-83}$

One of the first indications that MRI could predict knee replacement came from a trial recruiting 123 patients with symptomatic osteoarthritis. ${ }^{73}$ MRI assessment indicated that every $1 \%$ increase in the rate of tibial cartilage volume loss was associated with a $20 \%$ increase in the risk of knee replacement (95\% CI $10 \%$ to $30 \%$ ). Tibial cartilage loss was shown to be an independent predictor, and patients with the highest rates (cartilage loss $>8 \%$ ) had a seven times higher risk (OR 7.1, 95\% CI 1.4 to 36.5 ) of surgery. ${ }^{73}$ Another study from the same group showed that higher total cartilage defect scores increased the risk of joint replacement over 4 years by six times compared to those with lower scores (OR 6.0, 95\% CI 1.6 to 22.3). ${ }^{74}$ This result was unaffected by a variety of possible confounders, including radiographic severity.

The presence of BML has also been found to predict progression to knee replacement independently. A study ${ }^{75}$ reviewing 381 cases in a database of approximately 4000 MRI identified 25 patients with osteoarthritis alone and 48 patients with osteoarthritis and BML. They reported that the patients with BML were 8.95 times more likely to undergo knee replacement within 3 years $(p=0.016){ }^{75}$ The association was particularly strong for individuals with diffuse BML (ie, occupying most or all of the femur or tibial plateau), who were 13 times more likely to progress to surgery $(p<0.01)$. These authors failed to detect a correlation between cartilage loss or meniscal tears and knee replacement. ${ }^{75}$ In other studies, in which $15 \%$ of symptomatic osteoarthritis patients went on to have knee replacement over 4 years, ${ }^{77} 78$ MRI evaluation showed a progressive increase in the risk of knee replacement as bone abnormalities progressed from patients with no BML, to those with BML, and then to those with BML and cysts. The results correlated well with cartilage loss. For every one unit of BML severity score at baseline, there was an increase of $1.14 \%$ (95\% CI $0.29 \%$ to
$1.87 \%, \mathrm{p}=0.01)$ in cartilage loss. ${ }^{78}$ Similar observations have been made in a community study, ${ }^{80}$ which also demonstrated that the presence of BML in the right knee predicted the occurrence of joint replacement in both the left and the right knees.

One of the first RCT to use assessment with MRI, as opposed to radiography, comparing treatment with licofelone versus naproxen showed that MRI cartilage volume loss was a good measure for the analysis of DMOAD in knee osteoarthritis, and that $14.6 \%$ of the patients had a knee replacement in the 47 years ${ }^{79}$ following enrolment in the original trial. ${ }^{84}$ The presence of the following features on MRI at baseline was shown to be strongly predictive of knee replacement: BML in the medial compartment $(p=0.0001)$, severe medial meniscal tear $(p=0.004)$ and medial meniscal extrusion $(p=0.013)$. The changes in cartilage volume loss in the medial compartment at 2 years were also associated with knee replacement within 6 years $(p=0.005) .{ }^{79}$ Similar results were found in a trial with chondroitin sulfate, which was found to reduce the cartilage volume loss and $\mathrm{BML}^{85}$ as well as total knee replacement. ${ }^{86}$ Moreover, further results are expected from the analysis of the MRI data on the phase III strontium ranelate knee trial (SEKOIA). ${ }^{87}$

The OAI is the largest natural history study of osteoarthritis to date. This ongoing observational study is following a cohort of 4796 subjects aged 45-79 years, with or at risk of knee osteoarthritis. Within this cohort, 165 (3.5\%) subjects had a knee replacement by 4 years. ${ }^{76}$ Patients with greater loss of cartilage thickness in the central and total medial tibiofemoral compartments were more likely to progress to surgery than controls (area under the curve (AUC) 0.59 , 95\% CI 0.52 to 0.67 , $\mathrm{p}=0.006$ and AUC $0.58,95 \%$ CI 0.50 to $0.65, \mathrm{p}=0.016$, respectively). Cartilage thickness loss appeared to be the strongest longitudinal predictor, while the area of denuded bone was the best cross-sectional predictor. When these results were stratified by KL grade, the MRI parameters were the most predictive in patients with KL grade 2 knees; however, they depend on the use of radiographic KL grade as a measure of severity, even though only 25 patients were classified as KL grade 2 or lower. It is noteworthy that the results appear to be better for measurements in the central tibiofemoral compartment than for the global values. ${ }^{76}$ Structural endpoints other than those in cartilage have also been explored using semiquantitative MRI methods in the OAI cohort. ${ }^{81-83}$ When compared with controls matched for KL grade, age, body mass index and gender, knee replacement had increased odds of large BML in the medial femur and/or tibia before surgery. ${ }^{81}$ Moreover, they also had increased odds for worsening of BML size in three or more subregions in the medial tibiofemoral compartment. ${ }^{81}$ The presence of maceration of the meniscal body and of the medial posterior horn was more likely in knees that received knee replacement than in control knees. ${ }^{82}$ Risk of knee replacement was increased when a maximum grade of meniscal maceration was present in any of the analysed medial meniscal locations. ${ }^{82}$ Knees undergoing knee replacement were more likely to have effusion synovitis before surgery and worsening of both Hoffa synovitis and effusion synovitis longitudinally compared with control knees. ${ }^{83}$

Together, these results imply that MRI parameters including cartilage volume and thickness, semiquantitative scoring of cartilage defects, BML, meniscal lesions and synovitis could be useful additions to a model of knee replacement. Comparison of results for radiographic JSN and cartilage volume loss in the medial compartment on MRI over 2 years $^{79}$ suggests that they have similar predictive value for knee replacement within 6 years of follow-up (JSN, OR 15.45, 95\% CI 1.98 to 120.39 , 
Table 1 Studies exploring the predictive value of MRI parameters and knee replacement

\begin{tabular}{|c|c|c|c|}
\hline Study & Design/patient characteristics & MRI parameter & Main results \\
\hline Cicuttini et $a l^{73}$ & $\begin{array}{l}\text { Observational study } \\
123 \text { patients with osteoarthritis } \\
113 \text { completers at } 2 \text { years } \\
18(16 \%) \text { knee replacements over } \\
4 \text { years }\end{array}$ & $\begin{array}{l}\text { Quantitative MRI } \\
\text { Tibial cartilage volume loss over } 2 \text { years }\end{array}$ & $\begin{array}{l}\text { - } 1 \% \text { increase in tibial cartilage volume loss was associated with a } \\
20 \% \text { increase in risk for surgery (95\% CI } 10 \% \text { to } 30 \%) \\
\text { Patients with tibial cartilage volume loss }>8 \% \text { had higher risk } \\
\text { for surgery than those with }>3 \% \text { (OR, } 7.1,95 \% \mathrm{Cl} 1.4 \text { to } 36.5)\end{array}$ \\
\hline Wluka et $a l^{74}$ & $\begin{array}{l}\text { Observational study } \\
117 \text { patients with knee osteoarthritis } \\
18(15 \%) \text { knee replacements over } \\
4 \text { years }\end{array}$ & $\begin{array}{l}\text { Semiquantitative MRI } \\
\text { Cartilage defect score }\end{array}$ & $\begin{array}{l}\text { Higher cartilage defect scores ( } 8 \text { to } 15) \text { were associated with a } \\
\text { higher risk for surgery than lower scores (2 to } 7) \text { (OR, 6.0, 95\% } \\
\text { Cl } 1.6 \text { to 22.3) }\end{array}$ \\
\hline Scher et $a l^{75}$ & $\begin{array}{l}\text { Observational study } \\
25 \text { patients with knee osteoarthritis } \\
48 \text { patients with knee osteoarthritis } \\
\text { and BML } \\
15(21 \%) \text { knee replacements over } \\
3 \text { years }\end{array}$ & $\begin{array}{l}\text { Semiquantitative MRI } \\
\text { BML }\end{array}$ & $\begin{array}{l}\text { BML placed patients at higher risk for surgery (OR, } 8.95,95 \% \mathrm{Cl} \\
1.49 \text { to } 53.68) \\
\text { - Global BML placed patients at even higher risk (OR, 13.04, 95\% } \\
\text { Cl } 2.06 \text { to } 82.58) \\
\text { - No correlation for cartilage loss or meniscal change }\end{array}$ \\
\hline $\begin{array}{l}\text { Tanamas } \\
\text { et } \mathrm{al}^{77} 78\end{array}$ & $\begin{array}{l}\text { Observational study } \\
109 \text { patients with knee osteoarthritis } \\
16(15 \%) \text { knee replacements over } \\
4 \text { years }\end{array}$ & $\begin{array}{l}\text { Quantitative MRI } \\
\text { BML and bone cysts }\end{array}$ & $\begin{array}{l}\text { BML increased risk for surgery }(\mathrm{OR}, 1.57,95 \% \mathrm{Cl} 1.04 \text { to } 2.35 \text { ) } \\
\text { Both } \mathrm{BML} \text { and bone cysts in the medial compartment further } \\
\text { increased risk for surgery (OR, } 1.99,95 \% \mathrm{Cl} 1.01 \text { to } 3.90 \text { ) }\end{array}$ \\
\hline Dore et $a^{80}$ & $\begin{array}{l}\text { Community study } \\
395 \text { subjects } \\
12(3 \%) \text { knee replacements over } \\
5 \text { years }\end{array}$ & $\begin{array}{l}\text { Quantitative MRI } \\
\text { BML (right knee) }\end{array}$ & $\begin{array}{l}\text { BML in right knee predicted surgery in both knees (right knee } \\
\mathrm{OR}, 22.63,95 \% \mathrm{Cl} 3.72 \text { to } \infty \text {; left knee, } \mathrm{OR}, 12.85,95 \% \mathrm{Cl} \\
1.82 \text { to } 90.91 \text { ) } \\
\text { BML in right knee predicted surgery in both knees (right knee } \\
\mathrm{OR}, 2.88,95 \% \mathrm{Cl} 1.84 \text { to } 4.52 \text {; left knee, } \mathrm{OR}, 2.78,95 \% \mathrm{Cl} 1.58 \\
\text { to } 4.90 \text { ) }\end{array}$ \\
\hline Raynauld et $a l^{79}$ & $\begin{array}{l}\text { Randomised controlled trial } \\
\text { population } \\
161 \text { patients with knee osteoarthritis } \\
18(15 \%) \text { knee replacements } \\
\text { between } 4 \text { and } 7 \text { years }\end{array}$ & $\begin{array}{l}\text { Semiquantitative MRI } \\
\text { BML, meniscal tears, and meniscal } \\
\text { lesions } \\
\text { Quantitative MRI } \\
\text { Change in cartilage volume over } 2 \text { years }\end{array}$ & $\begin{array}{l}\text { The strongest predictors of surgery were medial BML (OR, } 1.48 \text {, } \\
95 \% \mathrm{Cl} 1.21 \text { to } 1.82) \text {, severe medial meniscal tears (OR, } 5.69 \text {, } \\
95 \% \mathrm{Cl} 1.75 \text { to } 18.49) \text {, and medial meniscal extrusion (OR, } 4.06 \text {, } \\
95 \% \mathrm{Cl} 1.35 \text { to } 12.23 \text { ) } \\
\text { Medial cartilage volume loss was also a strong predictor (OR, } \\
18.70,95 \% \mathrm{Cl} 2.40 \text { to } 145.67 \text { ) }\end{array}$ \\
\hline Eckstein et $a l^{76}$ & $\begin{array}{l}\text { Case-control study (Osteoarthritis } \\
\text { Initiative) } \\
4796 \text { patients with/at risk of knee } \\
\text { osteoarthritis } \\
165(3.5 \%) \text { knee replacements over } \\
4 \text { years } \\
\text { Controls without surgery }\end{array}$ & $\begin{array}{l}\text { Quantitative MRI } \\
\text { Change in cartilage thickness and area of } \\
\text { denuded bone from baseline to just } \\
\text { before surgery }\end{array}$ & $\begin{array}{l}\text { Patients with greater loss of cartilage thickness in central and } \\
\text { total medial compartments had greater risk for surgery than } \\
\text { controls (AUC, } 0.59,95 \% \mathrm{Cl} 0.52 \text { to } 0.67, \mathrm{p}=0.006 \text {; and AUC } \\
0.58,95 \% \mathrm{Cl} 0.50 \text { to } 0.65, \mathrm{p}=0.016 \text {, respectively) } \\
\text { Cartilage thickness loss appeared to be the strongest } \\
\text { longitudinal predictor, while area of denuded bone was the best } \\
\text { cross-sectional predictor }\end{array}$ \\
\hline Roemer et a $\left.\right|^{81}$ & $\begin{array}{l}\text { Case-control study (Osteoarthritis } \\
\text { Initiative) } \\
4796 \text { patients with/at risk of knee } \\
\text { osteoarthritis } \\
121 \text { knee replacements over } 4 \text { years } \\
121 \text { matched controls without } \\
\text { surgery }\end{array}$ & $\begin{array}{l}\text { Semiquantitative MRI } \\
\text { BML }\end{array}$ & $\begin{array}{l}\text { Worsening of BML size in } \geq 3 \text { subregions in the medial } \\
\text { tibiofemoral compartment was associated with increased odds of } \\
\text { knee replacement compared to knees without worsening in any } \\
\text { subregion in the same compartment (OR } 3.35,95 \% \mathrm{Cl} 1.14 \text { to } \\
\text { 9.82) }\end{array}$ \\
\hline Roemer et a $\left.\right|^{82}$ & $\begin{array}{l}\text { Case-control study (Osteoarthritis } \\
\text { Initiative) } \\
4796 \text { patients with/at risk of knee } \\
\text { osteoarthritis } \\
121 \text { knee replacements over } 4 \text { years } \\
121 \text { matched controls without } \\
\text { surgery }\end{array}$ & $\begin{array}{l}\text { Semiquantitative MRI } \\
\text { Meniscal damage }\end{array}$ & $\begin{array}{l}\text { Maceration of medial meniscal body (OR } 2.78,95 \% \mathrm{Cl} 1.50 \text { to } \\
5.16), \text { maceration of the posterior horn (OR } 2.20,95 \% \mathrm{Cl} 1.07 \\
\text { to } 4.53) \text {, and maximum grade meniscal maceration in any } \\
\text { location (OR } 2.96,95 \% \mathrm{Cl} 1.51 \text { to } 5.82 \text { ) were associated with } \\
\text { higher odds of knee replacement than knees without these } \\
\text { lesions }\end{array}$ \\
\hline Guermazi et a/ $/^{83}$ & $\begin{array}{l}\text { Case-control study (Osteoarthritis } \\
\text { Initiative) } \\
4796 \text { patients with/at risk of knee } \\
\text { osteoarthritis } \\
121 \text { knee replacements over } 4 \text { years } \\
121 \text { matched controls without } \\
\text { surgery }\end{array}$ & $\begin{array}{l}\text { Semiquantitative MRI } \\
\text { Hoffa synovitis and effusion synovitis }\end{array}$ & $\begin{array}{l}\text { Knees that underwent knee replacement were more likely to } \\
\text { have effusion-synovitis of any grade (OR } 2.45,95 \% \mathrm{Cl} 1.22 \text { to } \\
4.95) \text { than controls } \\
\text { Knees that underwent knee replacement were more likely to } \\
\text { have worsening Hoffa- (OR } 7.00,95 \% \mathrm{Cl} 1.59 \text { to } 30.80) \text { and } \\
\text { effusion synovitis (OR } 2.27,95 \% \mathrm{Cl} 1.11 \text { to } 4.62) \text { than controls }\end{array}$ \\
\hline
\end{tabular}

BML, bone marrow lesions.

$\mathrm{p}=0.009$ versus cartilage volume loss, OR $18.70,95 \%$ CI 2.40 to $145.67, \mathrm{p}=0.005)$. However, preliminary results from the OAI support a better predictive value of MRI cartilage volume loss over JSN in early radiographic osteoarthritis. ${ }^{88}$ Further research will show whether MRI is more sensitive than radiography for knee replacement.
The individual contributions of pain, functional impairment and structure in the progression to surgery have yet to be determined. In a recent study, ${ }^{79}$ a strong signal of less improvement in symptoms, particularly the Western Ontario and McMaster Universities arthritis index (WOMAC) pain, observed in the 2-year follow-up predicted the subsequent occurrence of a total 
knee replacement at 6 years following study inception. Recent publications have demonstrated that cartilage loss in knee osteoarthritis patients is associated with worsening of pain. According to two recent publications, cartilage volume loss was predictive of the later occurrence of total knee replacement in multivariate models that included age, gender, body mass index and WOMAC pain. ${ }^{73} 79$ This demonstrates that such MRI findings independently predicted total knee replacement occurrences regardless of patients' symptom level.

\section{DISCUSSION}

The non-invasive technique of MRI allows for comprehensive imaging of joint structures and structural changes over time in patients with knee osteoarthritis. A number of semiquantitative scoring methods and quantitative technologies have been developed and validated. They have been shown to be reliable in the assessment of structural changes cross-sectionally and longitudinally.

The evidence for the predictive value of MRI parameters for knee replacement has increased over the past few years (table 1). ${ }^{33}$ 73-83 Studies linking MRI parameters with joint replacement were performed using both quantitative and semiquantitative techniques. One recent RCT showed that MRI quantitative methodology may be more sensitive to change during a 2-year observation period than the semiquantitative scoring methods to assess cartilage loss in the context of clinical trials. ${ }^{34}$ This relative lack of sensitivity to change compared with quantitative methods is a known weakness of semiquantitative assessments. ${ }^{15}$ However, both appear good options in the place of joint replacement to be used in RCT of DMOAD.

Review of the currently available studies suggests that medial compartment cartilage volume/thickness assessment by MRI is predictive of joint replacement. ${ }^{73} 7679$ This forms the basis of the first ESCEO statement in box 1. The MRI equivalent to radiographic JSN, in terms of a longitudinal parameter, would be medial compartment cartilage loss. Other MRI parameters, such as the assessment of cartilage defects, BML, meniscal lesions and synovitis also seem to be predictive of knee replacement, ${ }^{74} 75$ 77-83 and may be useful as structural endpoints in trials of DMOAD, which underlies the second ESCEO statement in box 1. Further research will determine the value of these parameters.

Another dimension to consider is exactly how MRI should be used in RCT in knee osteoarthritis. In this context, we should note that patient selection in RCT is usually driven by regulatory considerations. ${ }^{8} 9$ The European and American regulatory

Box 1 Economic aspects of osteoporosis and osteoarthritis statements on the predictive value of MRI for hard outcomes in knee osteoarthritis

Statement 1: Medial compartment cartilage volume/thickness loss may be a valid structural endpoint in RCT in knee osteoarthritis involving patients with late-stage osteoarthritis. Statement 2: Other MRI outcomes including assessment of cartilage defects, bone marrow lesions, meniscal lesions and synovitis may also predict knee replacement, and may potentially serve as structural endpoints in clinical trials. Statement 3: Integration of the information contained in MRI could eventually lead to a predictive tool for knee replacement. agencies require evidence of an impact on radiographic structure (JSN) as well as an effect on pain and function for authorisation as a DMOAD, and so RCT are generally designed with this in mind. This is unlikely to change in the absence of a step change in pharmacological therapy, which could provide the stimulus for regulatory change from radiographic criteria to MRI assessment. Nevertheless, it is recommended that MRI be used as a secondary DMOAD endpoint in RCT.

Reduction in knee replacement is a reasonable therapeutic goal in the management of knee osteoarthritis, but using knee replacement as an endpoint in clinical trials is limited by confounders. Virtual knee replacement (ie, structural damage endpoint justifying knee replacement) is an attractive alternative. ${ }^{71}$ However, some of the definitions based on radiographic criteria lack discriminative power, and would necessitate large study populations and long follow-up times. The use of MRI-based virtual knee replacement promises to be more powerful, and further research with sufficiently powered MRI studies with adequate follow-up times (ie, at least 12 months) could verify this. This could eventually lead to revision of the definition of virtual knee replacement to include MRI criteria, which constitutes the third ESCEO statement (box 1).

There are a number of other issues that need to be addressed before MRI parameters can be used as surrogate outcomes in knee osteoarthritis. There is still room for better standardisation and validation of MRI measurements, which may improve its potential for interpreting the progression of disease on a large scale. Although MRI is at this time an expensive technique and can only be performed in relatively small patient groups, data indicate that with the use of MRI in RCT, fewer patients would probably be needed to reach statistical power.

\section{CONCLUSION}

The ESCEO group has reviewed current knowledge on the predictive value of MRI in the occurrence of joint replacement surgery in knee osteoarthritis. The ESCEO considers that MRI is a viable alternative to radiography for evaluating structural changes in knee osteoarthritis. Currently, MRI parameters such as medial compartment cartilage volume/thickness loss, and the assessment of cartilage defects, BML, meniscal lesions and synovitis seem to be able to predict progression to knee replacement surgery.

\section{Author affiliations}

${ }^{1}$ Osteoarthritis Research Unit, University of Montreal Hospital Research Centre (CRCHUM), Notre-Dame Hospital, Montreal, Quebec, Canada

${ }^{2}$ MRC Lifecourse Epidemiology Unit, University of Southampton, Southampton, UK ${ }^{3}$ NIHR Musculoskeletal Biomedical Research Unit, University of Oxford, Oxford, UK

${ }^{4}$ Spire Sciences, LLC, San Francisco, California, USA

${ }^{5}$ Department of Public Health, Epidemiology and Health Economics, University of

Liège, Liège, Belgium

${ }^{6}$ Metabolic Bone Unit, Department of Internal Medicine, University of Florence,

Florence, Italy

${ }^{7}$ Service de Rhumatologie et Pathologie Osseuse, INSERM UMR 1033 and Université de Lyon, Hôpital Edouard Herriot, Lyon, France

${ }^{8}$ School of Public Health and Preventive Medicine, Monash University, Melbourne, Australia

${ }^{9}$ Division of Musculoskeletal Disease, University of Leeds and NIHR Leeds

Musculoskeletal Biomedical Research Unit, Leeds, UK

${ }^{10}$ Academic Rheumatology, University of Nottingham, Clinical Sciences Building, Nottingham City Hospital, Nottingham, UK

${ }^{11}$ Departments of Radiology, Medicine, Epidemiology and Orthopedic Surgery,

University of California, San Francisco, California, USA

${ }^{12}$ Clinical Research Unit, Rottapharm|Madaus Group, Monza, Italy

${ }^{13}$ Departments of Medicine and Epidemiology and Public Health, University of Maryland School of Medicine, Baltimore, Maryland, USA

${ }^{14}$ Department of Rheumatology, Royal North Shore Hospital and Northern Clinical School, University of Sydney, Sydney, New South Wales, Australia 
${ }^{15}$ WHO Collaborating Centre for Metabolic Bone Diseases, University of Sheffield Medical School, Sheffield, UK

${ }^{16}$ Department of Rheumatology, Leiden University Medical Center, Leiden, The Netherlands

${ }^{17}$ Department of Radiology, Bone and Joint Imaging Unit, Lariboisière Hospital, Assistance publique des hôpitaux de Paris and Université Paris-Diderot, Paris, France ${ }^{18}$ Division of Rheumatology, Tufts Medical Center, Boston, Massachusetts, USA

${ }^{19}$ Department of Epidemiology and Biostatistics, OAI Coordinating Center, University of California, San Francisco, California, USA

${ }^{20}$ Division of Bone Diseases, Geneva University Hospital and Faculty of Medicine, Geneva, Switzerland

${ }^{21}$ Medical Faculty, Department of Orthopaedic Surgery, University of Dusseldorf, Dusseldorf, Germany

${ }^{22}$ Department of Radiology, University of Erlangen, Erlangen, Germany

${ }^{23}$ Department of Radiology, Quantitative Imaging Center, Boston University School of Medicine, Boston, Massachusetts, USA

Acknowledgements The authors wish to thank Sarah Novack for editorial assistance (funded by the ESCEO). ESCEO is the European Society for Clinical and Economic Aspect of Osteoporosis and Osteoarthritis, a not-for-profit organisation dedicated to a close interaction between clinical scientists dealing with bone, joint and muscle disorders, the pharmaceutical industry developing new compounds in this field, regulators responsible for the registration of such drugs and health policy makers, to integrate the management of osteoporosis, osteoarthritis, frailty and sarcopenia within the comprehensive perspective of health resources utilisation. ESCEO is mainly funded through the resources generated by the World Congress on Osteoporosis, Osteoarthritis and Musculoskeletal Diseases (WCO-IOF-ESCEO), formerly the European Congress on Osteoporosis and Osteoarthritis, which ESCEO is organising, on a yearly basis, together with the International Osteoporosis Foundation (IOF) and which is now the largest event, worldwide, fully dedicated to the clinical and economic aspects of osteoporosis and osteoarthritis.

Contributors All the authors have read and approved the manuscript and contributed to the review. J-PP and CC were joint first authors.

Funding The work was supported by the European Society for Clinical and Economic Aspects of Osteoporosis and Osteoarthritis (ESCEO).

Competing interests J-PP: Owner of ArthroLab Inc.; consulting fees from Bioibérica, Endocyte, Ferring, Merck, Pfizer, Servier, TRB Chemedica. CC: Consulting fees and paid advisory boards for Alliance for Better Bone Health, GlaxoSmithKline, Roche, Merck Sharp and Dohme, Lilly, Amgen, Wyeth, Novartis, Servier, and Nycomed. CP: Shareholder in Spire Sciences LLC; consultant for Abbott, Amgen, AstraZeneca, Biogen-Idec, Bristol Myers-Squibb, Celgene, Centocor, Crescendo, El Lilly and Company, Genentech, Genzyme, Johnson \& Johnson, Merck, Novartis, Pfizer, Rigel, Roche, Sanofi, UCB, Wyeth; employee of Spire Sciences LLC. J-YR: Consulting fees, paid advisory boards, lecture fees, and/or grant support from Servier, Novartis, Negma, Lilly, Wyeth, Amgen, GlaxoSmithKline, Roche, Merckle, Nycomed, NPS, Theramex, UCB, Merck Sharp and Dohme, Rottapharm, IBSA, Genevrier, Teijin, Teva, Ebewee Pharma, Zodiac, Analis, Novo-Nordisk, and Bristol Myers Squibb. M-LB: Support from Fondazione Italiana Ricerca Malattie Ossee and grants from Merck Sharpe \& Dohme, Nycomed, Roche, Glaxo, Eli Lilly, and Wyeth; speaker fees from Procter and Gamble, Merck Sharpe \& Dohme, Nycomed, and Wyeth. OB: Grant research: GlaxoSmithKline, IBSA, Merck Sharp \& Dohme, Theramex, Novartis, Pfizer, Rottapharm, Servier; consulting or lecture fees: IBSA, Rottapharm, Servier; reimbursement for attending meetings: IBSA, Merck Sharp \& Dohme, Novartis, Pfizer, Rottapharm, Theramex, Servier. RC: Research grant: Merck, Chugai-Roche, Warner-Chilcott; consulting and/or lecture fees: Servier, Chugai-Roche, Novartis, Amgen, Pfizer, UCB, Bioibérica. FC: None. PGC: Speaker bureaux or advisory boards for Janssen, Merck, Pfizer and Servier. MD: Consulting fees and paid advisory boards for Pfizer and Servier. HG: Consultant and/or advisory board for Servier, Amgen, Merck, Lilly, Pfizer, GSK, BMS, Novartis, Roche, Takeda, Janssen, ONO, and Radius. GG: None. MCH: Consulting and/or lecture fees from Abbott Laboratories, Bioibérica SA, Eli Lilly, IBSA, Merck \& Co., Pfizer and Rottapharm/Madaus. DJH: Consulting fees from Bioibérica. JAK: Consulting fees, paid advisory boards, lecture fees, and/or grant support from the majority of companies concerned with skeletal metabolism. MK: Consulting fees and research grants from Servier, Pfizer. J-DL: Consulting fees, paid advisory boards, lecture fees, and/or grant support from Servier, Wyeth, Roche-Chugaï, Amgen, and Pierre Fabre. TM: Consulting fees from Bioibérica, Sanofi, Flexion, Wintherix. MN: Consulting fees from Amgen and grant support from Johnson \& Johnson. J-PR: Consulting fees and lecture fees from AbbVie, Pfizer, Servier, Novartis, Lilly, Amgen,

GlaxoSmithKline, Roche, UCB, Merck and Bristol Myers Squibb. RR: Consulting and lecture fees for Merck Sharp and Dohme, Eli Lilly, Amgen, Novartis, Servier, Nycomed, Nestlé, and Danone. CZ: None. FR: Consulting fees from Merck Serono and National Institute of Health; chief medical officer of Boston Imaging Core Lab, LLC. JM-P: Owner of ArthroLab Inc.; consulting fees from Bioibérica, Endocyte, Ferring, Merck, Pfizer, Servier, TRB Chemedica. AG: Consulting fees from Novartis,
Stryker, Genzyme, AstraZeneca, and Merck Serono; president of Boston Imaging Core Lab, LLC.

Provenance and peer review Not commissioned; externally peer reviewed.

\section{REFERENCES}

1 Bijlsma JW, Berenbaum F, Lafeber FP. Osteoarthritis: an update with relevance for clinical practice. Lancet 2011;377:2115-26.

2 Altman RD, Gold GE. Atlas of individual radiographic features in osteoarthritis, revised. Osteoarthritis Cartilage 2007;15(Suppl. A):A1-56.

3 Hunter DJ, Guermazi A. Imaging techniques in osteoarthritis. PM R 2012;4:S68-74.

4 Teichtahl AJ, Wluka AE, Davies-Tuck ML, et al. Imaging of knee osteoarthritis. Best Pract Res Clin Rheumatol 2008;22:1061-74.

5 Guermazi A, Roemer FW, Burstein D, et al. Why radiography should no longer be considered a surrogate outcome measure for longitudinal assessment of cartilage in knee osteoarthritis. Arthritis Res Ther 2011;13:247.

6 Guermazi A, Niu J, Hayashi D, et al. Prevalence of abnormalities in knees detected by MRI in adults without knee osteoarthritis: population based observational study (Framingham Osteoarthritis Study). BMJ 2012;345:e5339.

7 Peterfy C, Li J, Zaim S, et al. Comparison of fixed-flexion positioning with fluoroscopic semi-flexed positioning for quantifying radiographic joint-space width in the knee: test-retest reproducibility. Skeletal Radiol 2003;32:128-32.

8 Committee for Medicinal Products for Human Use. Guideline on clinical investigation of medicinal products used in the treatment of osteoarthritis. 2010. http://www.ema.europa.eu (accessed 19 Sep 2012).

9 Food and Drug Administration. Guidance for industry. Clinical development programs for drugs, devices, and biological products intended for the treatment of osteoarthritis. 2011. http://www.fda.gov (accessed 12 Jun 2012).

10 Menashe L, Hirko K, Losina E, et al. The diagnostic performance of MRI in osteoarthritis: a systematic review and meta-analysis. Osteoarthritis Cartilage 2012;20:13-21.

11 Hunter DJ, Zhang W, Conaghan PG, et al. Responsiveness and reliability of MRI in knee osteoarthritis: a meta-analysis of published evidence. Osteoarthritis Cartilage 2011;19:589-605.

12 Wang $Y$, Wluka $A E$, Jones $G$, et al. Use magnetic resonance imaging to assess articular cartilage. Ther Adv Musculoskelet Dis 2012;4:77-97.

13 Peterfy CG, Schneider E, Nevitt M. The osteoarthritis initiative: report on the design rationale for the magnetic resonance imaging protocol for the knee. Osteoarthritis Cartilage 2008;16:1433-41.

$14 \mathrm{Xu}$ L, Hayashi D, Roemer FW, et al. Magnetic resonance imaging of subchondral bone marrow lesions in association with osteoarthritis. Semin Arthritis Rheum 2012:42:105-18

15 Guermazi A, Roemer FW, Haugen IK, et al. MRI-based semiquantitative scoring of joint pathology in osteoarthritis. Nat Rev Rheumatol 2013;9:236-51.

16 Hunter DJ, Lo GH, Gale D, et al. The reliability of a new scoring system for knee osteoarthritis MRI and the validity of bone marrow lesion assessment: BLOKS (Boston Leeds Osteoarthritis Knee Score). Ann Rheum Dis 2008;67:206-11.

17 Peterfy CG, Guermazi A, Zaim S, et al. Whole-Organ Magnetic Resonance Imaging Score (WORMS) of the knee in osteoarthritis. Osteoarthritis Cartilage 2004;12:177-90.

18 Hunter DJ, Guermazi A, Lo GH, et al. Evolution of semi-quantitative whole joint assessment of knee OA: MOAKS (MRI Osteoarthritis Knee Score). Osteoarthritis Cartilage 2011;19:990-1002.

19 Lynch JA, Roemer FW, Nevitt MC, et al. Comparison of BLOKS and WORMS scoring systems part I. Cross sectional comparison of methods to assess cartilage morphology, meniscal damage and bone marrow lesions on knee MRI: data from the osteoarthritis initiative. Osteoarthritis Cartilage 2010;18:1393-401.

20 Felson DT, Lynch J, Guermazi A, et al. Comparison of BLOKS and WORMS scoring systems part II. Longitudinal assessment of knee MRIs for osteoarthritis and suggested approach based on their performance: data from the Osteoarthritis Initiative. Osteoarthritis Cartilage 2010;18:1402-7.

21 Roemer FW, Zhang Y, Niu J, et al. Tibiofemoral joint osteoarthritis: risk factors for MR-depicted fast cartilage loss over a 30-month period in the multicenter osteoarthritis study. Radiology 2009;252:772-80.

22 Roemer FW, Nevitt MC, Felson DT, et al. Predictive validity of within-grade scoring of longitudinal changes of MRI-based cartilage morphology and bone marrow lesion assessment in the tibio-femoral joint-the MOST study. Osteoarthritis Cartilage 2012;20:1391-8.

23 Dodin P, Pelletier JP, Martel-Pelletier J, et al. Automatic human knee cartilage segmentation from 3D magnetic resonance images. IEEE Trans Biomed Eng 2010;57:2699-711.

24 Kauffmann C, Gravel P, Godbout B, et al. Computer-aided method for quantification of cartilage thickness and volume changes using MRI: validation study using a synthetic model. IEEE Trans Biomed Eng 2003;50:978-88.

25 Cicuttini F, Forbes A, Morris K, et al. Gender differences in knee cartilage volume as measured by magnetic resonance imaging. Osteoarthritis Cartilage 1999;7:265-71. 
26 Peterfy CG, Van Dijke CF, Janzen DL, et al. Quantification of articular cartilage in the knee with pulsed saturation transfer subtraction and fat-suppressed MR imaging: optimization and validation. Radiology 1994;192:485-91.

27 Li W, Abram F, Pelletier JP, et al. Fully automated system for the quantification of human osteoarthritic knee joint effusion volume using magnetic resonance imaging. Arthritis Res Ther 2010;12:R173.

28 Krasnokutsky S, Belitskaya-Levy I, Bencardino J, et al. Quantitative magnetic resonance imaging evidence of synovial proliferation is associated with radiographic severity of knee osteoarthritis. Arthritis Rheum 2011;63:2983-91.

29 Dodin P, Abram F, Pelletier JP, et al. A fully automated system for quantification of knee bone marrow lesions using MRI and the Osteoarthritis Initiative (OAI) cohort (public datasets). J Biomed Graph Comput 2013;3:51-65.

30 Eckstein F, Wirth W. Quantitative cartilage imaging in knee osteoarthritis. Arthritis 2011:2011:475684.

31 Food and Drug Administration. FDA: New warnings required on use of gadolinium-based contrast agents. 2010. http://www.fda.gov (accessed 12 Dec 2012)

32 Bruyere $\mathrm{O}$, Genant $\mathrm{H}$, Kothari $\mathrm{M}$, et al. Longitudinal study of magnetic resonance imaging and standard $\mathrm{X}$-rays to assess disease progression in osteoarthritis. Osteoarthritis Cartilage 2007;15:98-103.

33 Hunter DJ, Zhang W, Conaghan PG, et al. Systematic review of the concurrent and predictive validity of MRI biomarkers in OA. Osteoarthritis Cartilage 2011;19:557-88

34 Wildi LM, Martel-Pelletier J, Abram F, et al. Assessment of cartilage changes over time in knee osteoarthritis disease-modifying osteoarthritis drug trials using semiquantitative and quantitative methods: pros and cons. Arthritis Care Res (Hoboken) 2013;65:686-94.

35 Raynauld JP, Martel-Pelletier J, Berthiaume MJ, et al. Quantitative magnetic resonance imaging evaluation of knee osteoarthritis progression over two years and correlation with clinical symptoms and radiologic changes. Arthritis Rheum 2004;50:476-87.

36 Eckstein F, Cicuttini F, Raynauld JP, et al. Magnetic resonance imaging (MRI) of articular cartilage in knee osteoarthritis (OA): morphological assessment. Osteoarthritis Cartilage 2006;14(Suppl. 1):46-75.

37 Roemer FW, Kwoh CK, Hannon MJ, et al. Semiquantitative assessment of focal cartilage damage at 3T MRI: a comparative study of dual echo at steady state (DESS) and intermediate-weighted (IW) fat suppressed fast spin echo sequences. Eur J Radiol 2011;80:e126-31.

38 Peterfy CG, Gold G, Eckstein F, et al. MRI protocols for whole-organ assessment of the knee in osteoarthritis. Osteoarthritis Cartilage 2006;14(Suppl. A):A95-111.

39 Raynauld JP, Martel-Pelletier J, Abram F, et al. Analysis of the precision and sensitivity to change of different approaches to assess cartilage loss by quantitative MRI in a longitudinal multicentre clinical trial in patients with knee osteoarthritis. Arthritis Res Ther 2008;10:R129.

40 Roemer FW, Kassim Javaid M, Guermazi A, et al. Anatomical distribution of synovitis in knee osteoarthritis and its association with joint effusion assessed on non-enhanced and contrast-enhanced MRI. Osteoarthritis Cartilage 2010;18:1269-74.

41 Baker K, Grainger A, Niu J, et al. Relation of synovitis to knee pain using contrast-enhanced MRIs. Ann Rheum Dis 2010;69:1779-83.

42 Guermazi A, Roemer FW, Hayashi D, et al. Assessment of synovitis with contrast-enhanced MRI using a whole-joint semiquantitative scoring system in people with, or at high risk of, knee osteoarthritis: the MOST study. Ann Rheum Dis 2011;70:805-11.

43 Pelletier JP, Raynauld JP, Abram F, et al. A new non-invasive method to assess synovitis severity in relation to symptoms and cartilage volume loss in knee osteoarthritis patients using MRI. Osteoarthritis Cartilage 2008;16(Suppl. 3):S8-13.

44 Loeuille D, Chary-Valckenaere I, Champigneulle J, et al. Macroscopic and microscopic features of synovial membrane inflammation in the osteoarthritic knee: correlating magnetic resonance imaging findings with disease severity. Arthritis Rheum 2005:52:3492-501.

45 Loeuille D, Sauliere N, Champigneulle J, et al. Comparing non-enhanced and enhanced sequences in the assessment of effusion and synovitis in knee $O A$ associations with clinical, macroscopic and microscopic features. Osteoarthritis Cartilage 2011;19:1433-9.

46 Roemer FW, Guermazi A, Zhang Y, et al. Hoffa's fat pad: evaluation on unenhanced MR images as a measure of patellofemoral synovitis in osteoarthritis. AJR Am J Roentgenol 2009;192:1696-700.

47 Habib S, Guermazi A, Ozonoff A, et al. MRI-based volumetric assessment of joint effusion in knee osteoarthritis using proton density-weighted fat-suppressed and T1-weighted contrast-enhanced fat-suppressed sequences. Skeletal Radiol 2011:40:1581-5.

48 Roemer FW, Felson DT, Wang K, et al. Co-localisation of non-cartilaginous articular pathology increases risk of cartilage loss in the tibiofemoral joint-the MOST study. Ann Rheum Dis 2013;72:942-8.

49 Zhang Y, Nevitt M, Niu J, et al. Fluctuation of knee pain and changes in bone marrow lesions, effusions, and synovitis on magnetic resonance imaging. Arthritis Rheum 2011;63:691-9.
50 Dore DA, Winzenberg TM, Ding C, et al. The association between objectively measured physical activity and knee structural change using MRI. Ann Rheum Dis 2013:72:1170-5.

51 Wluka AE, Wang Y, Davies-Tuck $M$, et al. Bone marrow lesions predict progression of cartilage defects and loss of cartilage volume in healthy middle-aged adults without knee pain over 2 years. Rheumatology (Oxford) 2008;47:1392-6.

52 Davies-Tuck ML, Wluka AE, Forbes $A$, et al. Development of bone marrow lesions is associated with adverse effects on knee cartilage while resolution is associated with improvement-a potential target for prevention of knee osteoarthritis: a longitudinal study. Arthritis Res Ther 2010;12:R10.

53 Felson DT, Niu J, Guermazi A, et al. Correlation of the development of knee pain with enlarging bone marrow lesions on magnetic resonance imaging. Arthritis Rheum 2007;56:2986-92.

54 Roemer FW, Guermazi A, Javaid MK, et al. Change in MRI-detected subchondral bone marrow lesions is associated with cartilage loss: the MOST Study. A longitudinal multicentre study of knee osteoarthritis. Ann Rheum Dis 2009:68:1461-5

55 Wildi LM, Raynauld JP, Martel-Pelletier J, et al. Relationship between bone marrow lesions, cartilage loss and pain in knee osteoarthritis: results from a randomised controlled clinical trial using MRI. Ann Rheum Dis 2010;69:2118-24.

56 Raynauld JP, Martel-Pelletier J, Berthiaume MJ, et al. Correlation between bone lesion changes and cartilage volume loss in patients with osteoarthritis of the knee as assessed by quantitative magnetic resonance imaging over a 24-month period. Ann Rheum Dis 2008;67:683-8.

57 Raynauld JP, Martel-Pelletier J, Berthiaume MJ, et al. Long term evaluation of disease progression through the quantitative magnetic resonance imaging of symptomatic knee osteoarthritis patients: correlation with clinical symptoms and radiographic changes. Arthritis Res Ther 2006;8:R21.

58 Pelletier JP, Raynauld JP, Berthiaume MJ, et al. Risk factors associated with the loss of cartilage volume on weight-bearing areas in knee osteoarthritis patients assessed by quantitative magnetic resonance imaging: a longitudinal study. Arthritis Res Ther 2007;9:R74.

59 Hayashi D, Guermazi A, Kwoh CK, et al. Semiquantitative assessment of subchondral bone marrow edema-like lesions and subchondral cysts of the knee at 3T MRI: a comparison between intermediate-weighted fat-suppressed spin echo and Dual Echo Steady State sequences. BMC Musculoskelet Disord 2011;12:198.

60 Raynauld JP, Wildi LM, Abram F, et al. J. Reliability and sensitivity to change in the assessment of bone marrow lesions in knee osteoarthritis patients of IW-TSE versus DESS magnetic resonance imaging seequences: longitudinal data from the Osteoarthritis Initiative (OAI) cohort. JBiSE 2013;6:337-45.

61 Englund M, Guermazi A, Roemer FW, et al. Meniscal tear in knees without surgery and the development of radiographic osteoarthritis among middle-aged and elderly persons: the Multicenter Osteoarthritis Study. Arthritis Rheum 2009:60:831-9.

62 Berthiaume MJ, Raynauld JP, Martel-Pelletier J, et al. Meniscal tear and extrusion are strongly associated with progression of symptomatic knee osteoarthritis as assessed by quantitative magnetic resonance imaging. Ann Rheum Dis 2005;64:556-63.

63 Englund M, Roemer FW, Hayashi D, et al. Meniscus pathology, osteoarthritis and the treatment controversy. Nat Rev Rheumatol 2012:8:412-19.

64 Chang A, Moisio K, Chmiel JS, et al. Subregional effects of meniscal tears on cartilage loss over 2 years in knee osteoarthritis. Ann Rheum Dis 2011;70:74-9.

$65 \mathrm{Kim} \mathrm{HA}$, Kim I, Song YW, et al. The association between meniscal and cruciate ligament damage and knee pain in community residents. Osteoarthritis Cartilage 2011:19:1422-8.

66 Crema MD, Roemer FW, Felson DT, et al. Factors associated with meniscal extrusion in knees with or at risk for osteoarthritis: the Multicenter Osteoarthritis Study. Radiology 2012;264:494-503.

67 OECD. Hip and knee replacement. Health at a Glance: Europe 2012. OECD Publishing, 2012. http://dx.doi.org/10.1787/9789264183896-37-en

68 Zhang W, Nuki G, Moskowitz RW, et al. OARSI recommendations for the management of hip and knee osteoarthritis: part III: changes in evidence following systematic cumulative update of research published through January 2009. Osteoarthritis Cartilage 2010;18:476-99.

69 OECD. Hip and knee replacement. Health at a Glance 2011, OECD indicators. OECD Publishing, 2011. http://dx.doi.org/10.1787/health glance-2011-en

70 Losina E, Walensky RP, Reichmann WM, et al. Impact of obesity and knee osteoarthritis on morbidity and mortality in older Americans. Ann Intern Med 2011;154:217-26.

71 Manno RL, Bingham CO III, Paternotte S, et al. OARSI-OMERACT initiative: defining thresholds for symptomatic severity and structural changes in disease modifying osteoarthritis drug (DMOAD) clinical trials. Osteoarthritis Cartilage 2012;20:93-101.

72 Conaghan PG, Hunter DJ, Maillefert JF, et al. Summary and recommendations of the OARSI FDA osteoarthritis Assessment of Structural Change Working Group. Osteoarthritis Cartilage 2011;19:606-10.

73 Cicuttini FM, Jones $\mathrm{G}$, Forbes $\mathrm{A}$, et al. Rate of cartilage loss at two years predicts subsequent total knee arthroplasty: a prospective study. Ann Rheum Dis 2004:63:1124-7. 
74 Wluka $A E$, Ding $C$, Jones $G$, et al. The clinical correlates of articular cartilage defects in symptomatic knee osteoarthritis: a prospective study. Rheumatology (Oxford) 2005;44:1311-16.

75 Scher C, Craig J, Nelson F. Bone marrow edema in the knee in osteoarthrosis and association with total knee arthroplasty within a three-year follow-up. Skeletal Radiol 2008;37:609-17.

76 Eckstein F, Kwoh CK, Boudreau RM, et al. Quantitative MRI measures of cartilage predict knee replacement: a case-control study from the Osteoarthritis Initiative. Ann Rheum Dis 2013;72:707-14.

77 Tanamas SK, Wluka AE, Pelletier JP, et al. The association between subchondral bone cysts and tibial cartilage volume and risk of joint replacement in people with knee osteoarthritis: a longitudinal study. Arthritis Res Ther 2010;12:R58.

78 Tanamas SK, Wluka AE, Pelletier JP, et al. Bone marrow lesions in people with knee osteoarthritis predict progression of disease and joint replacement: a longitudinal study. Rheumatology (Oxford) 2010;49:2413-19.

79 Raynauld JP, Martel-Pelletier J, Haraoui B, et al. Risk factors predictive of joint replacement in a 2-year multicentre clinical trial in knee osteoarthritis using MRI: results from over 6 years of observation. Ann Rheum Dis 2011;70:1382-8.

80 Dore D, Quinn S, Ding C, et al. Natural history and clinical significance of MRI-detected bone marrow lesions at the knee: a prospective study in community dwelling older adults. Arthritis Res Ther 2010;12:R223.

81 Roemer FW, Kwoh CK, Hunter DJ, et al. Large bone marrow lesions and worsening of bone marrow lesions in the medial tibio-femoral compartment are associated with knees undergoing total knee replacement-data from the osteoarthritis initiative. Osteoarthritis Cartilage 2012:20(Suppl. 1):S33-4.
82 Roemer FW, Kwoh CK, Hunter DJ, et al. Knees with medial meniscal pathology are more likely to undergo total knee replacement: a cross-sectional analysis from the Osteoarthritis Initiative. Osteoarthritis Cartilage 2012;20(Suppl. 1):S220.

83 Guermazi A, Kwoh CK, Hannon MJ, et al. Hoffa-synovitis and effusion-synovitis are associated with knees undergoing total knee replacement: data from the osteoarthritis initiative. Osteoarthritis Cartilage 2012;20(Suppl. 1):S235-6.

84 Raynauld JP, Martel-Pelletier J, Bias P, et al. Protective effects of licofelone, a 5-lipoxygenase and cyclo-oxygenase inhibitor, versus naproxen on cartilage loss in knee osteoarthritis: a first multicentre clinical trial using quantitative MRI. Ann Rheum Dis 2009:68:938-47.

85 Wildi LM, Raynauld JP, Martel-Pelletier J, et al. Chondroitin sulphate reduces both cartilage volume loss and bone marrow lesions in knee osteoarthritis patients starting as early as 6 months after initiation of therapy: a randomised, double-blind, placebo-controlled pilot study using MRI. Ann Rheum Dis 2011;70:982-9.

86 Raynauld JP, Martel-Pelletier J, Dorais M, et al. Total knee replacement as a knee osteoarthritis outcome: predictors derived from a 4 year long-term observation following a randomized clinical trial using chondroitin sulfate. CART 2013:4:219-226

87 Reginster JY, Badurski J, Bellamy N, et al. Efficacy and safety of strontium ranelate in the treatment of knee osteoarthritis: results of a double-blind, randomised placebo-controlled trial. Ann Rheum Dis 2013;72:179-86.

88 Eckstein F, Kwoh CK, Boudreau RM, et al. Does structural progression of knee osteoarthritis measured with magnetic resonance imaging or radiography predict knee replacement?-data from the osteoarthritis initiative. Arthritis Rheum 2012;64:S1041 


\section{ARD What is the predictive value of MRI for the occurrence of knee replacement surgery in knee osteoarthritis?}

J-P Pelletier, C Cooper, C Peterfy, J-Y Reginster, M-L Brandi, O Bruyère, R Chapurlat, F Cicuttini, P G Conaghan, M Doherty, H Genant, G Giacovelli, M C Hochberg, D J Hunter, J A Kanis, M Kloppenburg, J-D Laredo, T'McAlindon, M Nevitt, J-P Raynauld, R Rizzoli, C Zilkens, F W Roemer, J Martel-Pelletier and A Guermazi

Ann Rheum Dis 2013 72: 1594-1604 originally published online July 25, 2013

doi: 10.1136/annrheumdis-2013-203631

Updated information and services can be found at: http://ard.bmj.com/content/72/10/1594

References

Email alerting service

\section{These include:}

This article cites 83 articles, 22 of which you can access for free at: http://ard.bmj.com/content/72/10/1594\#BIBL

Receive free email alerts when new articles cite this article. Sign up in the box at the top right corner of the online article.

\section{Notes}

To request permissions go to:

http://group.bmj.com/group/rights-licensing/permissions

To order reprints go to:

http://journals.bmj.com/cgi/reprintform

To subscribe to BMJ go to:

http://group.bmj.com/subscribe/ 